\title{
Communicating, Narrating, and Focalizing Minds
}

\begin{abstract}
This chapter affords a broad conceptualization of communicating minds, which is essential for framing transmedial narration. It also suggests a methodical way of analyzing narrators and narratees that are external and internal to narratives. Distinctions are made between actual narrators/narratees and overarching and embedded virtual (represented) narrators/narratees in order to be able to discern both transmedial and media-specific narrative features. Whereas all narratives by definition require actual narrators and narratees, it is sometimes helpful to construe overarching virtual narrators or narratees that are internal to narratives and help in making sense of them. Narratives can also hold embedded virtual narrators and narratees creating stories within stories. Narrators additionally act as focalizers, delimiting the scope of narration in various ways.
\end{abstract}

Keywords Transmedial narration $\bullet$ Actual communicator $\bullet$ Actual narrator $\bullet$ Virtual communicator $\bullet$ Virtual narrator $\bullet$ Focalization

There is an extensive literature on the issue of narrators, their nature, and their possible existence or nonexistence (a good recent overview with a transmedial perspective can be found in Thon 2016: 125-166). Although I have profited in general terms from this literature, which will not be extensively discussed here, I will in this chapter form a conceptual frame-

(C) The Author(s) 2019 https://doi.org/10.1007/978-3-030-01294-6_5 
work that is suitable for using in the setting of all forms of communication by all kinds of media-not only narration and not only media types where the use of language is salient. However, narration will be pinpointed as a special case in order to get us back on the main track.

Although my suggested typologies in this chapter naturally resemble earlier categorizations in several ways, they are more flexible, precisely in the sense that they work for all media types. Given that narratives are conceptualized as virtual spheres formed in the perceiver's mind, which means that they are not determined to have any certain characteristics except for those stipulated by the definition of a story, they also allow for a pragmatic approach to the issue of narrators. I suggest that fruitless quarrels regarding whether certain kinds of narrators need to be present in various media types can be avoided by emphasizing the virtual nature of narratives and the modeling nature of the proposed typologies; the distinctions to be made in this chapter correspond to possible ways of construing narratives rather than to definite traits of narratives.

I will start by briefly presenting the contours and essential features of this conceptual framework and then discuss parts of it in some detail. This requires reemphasizing some general concepts that I have already introduced in this treatise. In Chap. 2 I distinguished between the intra- and extracommunicational domains and emphasized that they are utterly entwined but nevertheless dissimilar areas in the mind of the perceiver of media products. The point is to mark out a difference between the forming of cognitive import in ongoing communication and what precedes and surrounds it in the form of cognitive import stored in the mind. I call the intracommunicational domain, formed by communicative semiosis, a virtual sphere. Narratives are virtual spheres.

Regarding the extracommunicational domain, I have noted that vital parts of it are constituted by perception and interpretation of media products; previous communication is very much part of the background of ongoing communication. Thus, it may be said that the extracommunicational domain, the mental realm that precedes and surrounds the virtual sphere being formed in ongoing communication, consists of two complementary spheres: other virtual spheres (former interpretive results of communication) and what I propose to call the perceived actual sphere. The perceived actual sphere consists of earlier percepts outside of communication and interpretants resulting from semiosis triggered by these percepts. Every instance of communication is dependent on the experience of earlier encounters with things and phenomena in the world that have not been 
communicated by other minds. In summary, the perceived actual sphere is formed in one's mind through semiosis, immediate external perception, and also interoception, proprioception, and mental introspection.

\section{Communicating and Narrating Minds}

In Chap. 2 I also initially described communication in terms of a transfer of cognitive import between at least two minds, the producer's mind and the perceiver's mind, with the aid of an intermediate entity: the media product. After such a communicative transfer, there are mental configurations in the perceiver's mind - a virtual sphere-that to some extent are similar to those in the producer's mind. Acknowledging the presence of at least one producer's and one perceiver's mind in human communication is the starting point of the following distinctions among different kinds of communicating minds; distinctions that are vital for discerning some intricate conceptual structures of communication at large.

Before getting into details, I will present an overview of my proposed typologies in the form of two embryonic lists. The first is an inventory of different forms of communicating minds:

- A perceived actual communicating mind that is the actual producer of a media product = an actual communicator

- A perceived actual communicating mind that is the actual perceiver of a media product $=$ an actual communicatee

- An overarching virtual communicating mind that is the producer of overarching communication = an overarching virtual communicator

- An overarching virtual communicating mind that is the perceiver of overarching communication $=$ an overarching virtual communicatee

- An embedded virtual communicating mind that is the producer of embedded communication $=$ an embedded virtual communicator

- An embedded virtual communicating mind that is the perceiver of embedded communication $=$ an embedded virtual communicatee

- And so on; multiple layers of communication embedded in embedded communication.

The second list is a catalog of narrative minds. It is identical to the first list, except that communication in general is replaced with the special case of narration, meaning communication including stories: 
- A perceived actual communicating mind that is the actual producer of a narrative media product $=$ an actual narrator

- A perceived actual communicating mind that is the actual perceiver of a narrative media product $=$ an actual narratee

- An overarching virtual communicating mind that is the producer of overarching narration $=$ an overarching virtual narrator

- An overarching virtual communicating mind that is the perceiver of overarching narration $=$ an overarching virtual narratee

- An embedded virtual communicating mind that is the producer of embedded narration = an embedded virtual narrator

- An embedded virtual communicating mind that is the perceiver of embedded narration = an embedded virtual narratee

- And so on; multiple layers of narration embedded in embedded narration.

As narration is a transmedial form of communication, the terms 'narrator' and 'narratee', precisely as the terms 'communicator' and 'communicatee', shall be understood to refer to comprehensive communicative concepts useful for disentangling a range of functions and levels in narration in effectively all (not only verbal) media types.

I will now comment on each of these forms of communicative and narrative minds and explain their interrelations and why I think they are useful for conceptualizing certain aspects of communication in general and narration in particular.

A perceived actual communicating mind that is the actual producer of a media product = an actual communicator. If communication is at hand, a producer's mind is, by definition, present, at least initially. The producer's mind is responsible for the creation of a media product that may be perceived by some other mind either directly, as in face-to-face communication, or later, as when one watches an old movie. I suggest that a brief and simple term for this entity may be 'actual communicator'. However, it is more specifically a communicating mind that must be understood to stem, more or less directly, from a perceived actual sphere. Hence, it is perceived to be actual, which means that there will always necessarily remain some epistemological doubts regarding its actuality. In face-to-face communication, the perceiver is close to the producer's mind, in both time and space. Hence, the immediate perception of the activities of the body holding the producer's mind becomes part of the perceived actual sphere. In the case of watching an old movie, the perceiver is normally at 
a spatiotemporal distance from the producer's mind. Consequently, the mind of the producer (the actual communicator) may well be known to the perceiver only indirectly, perhaps through earlier communication. In other words, the perceived actual communicating mind stems from other virtual spheres (that always rely, to some extent, on perceived actual spheres). In any case, actual communicators are by definition parts of the extracommunicational domain. A media product may be produced by either one actual communicator (like speech) or several actual communicators (like most movies).

A perceived actual communicating mind that is the actual producer of a narrative media product = an actual narrator. All that was said above regarding actual communicators can be specified in terms of 'actual narrators'. In brief: if narration is at hand, a mind producing the narrative media product must exist; there is, by definition, at least one actual narrator emanating from the extracommunicational domain.

A perceived actual communicating mind that is the actual perceiver of a media product = an actual communicatee. Just as communication (as I define it) requires a producer's mind, it also requires a perceiver's mind. The perceiver's mind perceives the media product produced by the producer's mind and forms a virtual sphere through the mediation and representation of this media product. 'Actual communicatee' is a straightforward term for this entity. Although it may seem a bit strange, the actual communicatee is also, like the actual communicator, a perceived actual communicating mind: the mind that perceives a media product has an awareness and understanding of itself and this self-understanding stems from what precedes and surrounds ongoing communication: the extracommunicational domain. Thus, a mind that perceives and makes sense of a media product does so on the background of having perceived and made sense of, among other things, itself-immediately or mediated through earlier communication. Therefore, an actual communicatee is more precisely a perceived actual communicating mind, again necessarily tinted by epistemological doubts regarding its nature and actuality. A media product may be perceived by either one actual communicatee (like someone receiving a nudge indicating which direction she should go) or several actual communicatees (like many people listening to the same talk).

A perceived actual communicating mind that is the actual perceiver of a narrative media product $=$ an actual narratee. Again there is no need to repeat what has already been stated about the actual communicatee. What might be termed 'actual narratees' are the same as actual communicatees, 
except that they are more specifically involved in narration. If narration is at hand, at least one actual narratee perceiving the narrative media product must exist.

An overarching virtual communicating mind that is the producer of overarching communication $=$ an overarching virtual communicator. Communicators are minds that make communication possible by producing media products. In virtual spheres, however, communicators are virtual; they are representations of minds forming media products with semiotic qualities. A perceiver of a media product, an actual communicatee, who for various reasons has no knowledge of, access to, or interest in the actual communicator, is likely to form a virtual sphere that includes a construed overarching virtual communicating mind that is the producer of overarching communication-in brief, an 'overarching virtual communicator'-that helps in making the virtual sphere comprehensible. Otherwise, it might be difficult to make sense of media products whose producers are anonymous. Hence, the craving for internal coherence, for gestalt, can be satisfied with the aid of a construed overarching virtual communicator: odd details, vague connections, and apparent inconsistencies may be knitted together through the idea of a virtual communicating mind having certain ideas, peculiarities, purposes, unconscious drives, or ironic inclinations. Overarching virtual communicators may also be needed when perceiving media products formed collectively by several actual communicators and trying to understand the resulting virtual sphere as somehow consistent.

By definition, a virtual sphere can have only one overarching virtual communicator. As soon as one thinks in terms of several virtual communicators, they are automatically subordinated to either an overarching virtual communicator or an actual communicator. Whereas at least one actual communicator is needed to bring about communication, the overarching virtual communicator is an optional entity that can be conjured up in the virtual sphere to make sense of it. Although it emerges within the intracommunicational domains, it may well be very similar to communicating minds in the extracommunicational domain, such as the actual communicator. This is because, as noted earlier, all intracommunicational objects, including overarching virtual communicators, are ultimately made up of parts, combinations, or blends of extracommunicational objects.

The idea of an overarching virtual communicator accords well with what has long been known in literary theory as "implied author" (Booth 1961) and what in film studies is sometimes referred to as "voice" or 
"hypothetical filmmaker" (Alber 2010), although different authors construe these latter concepts in different ways. There have also been many philosophical discussions regarding the rather awkward question of the possibly factual existence of this kind of entity in various media (see Diehl 2009). In any case, the concept of overarching virtual communicator is fundamentally transmedial. This is because overarching virtual communicators are only indirectly represented by the sensory configurations of the media products, so to speak; they are formed in a later stage of the chains of semiosis and therefore independent of the modality modes of the media products.

An overarching virtual communicating mind that is the producer of overarching narration = an overarching virtual narrator. Narration is communication including narratives, and narrators are minds that make this possible by producing narrative media products. An 'overarching virtual narrator'-a brief term for an overarching virtual communicating mind that is the producer of overarching narration-should be understood in analogy with the concept of an overarching virtual communicator, except that an overarching virtual narrator is obviously relevant in the case of narration. Nothing much needs to be added here, except a brief terminological comment. As the term 'narrator' has been used mainly for media types including verbal language, the term 'monstrator' has been suggested for the realm of visual iconic media (Gaudreault 2009 [1988]). Although this term stands for a concept that corresponds quite well with the concept of overarching virtual narrator, it would be unfeasible to use different terms for all basic media types that harbor narratives. For that reason, I stick to the term (actual or virtual) 'narrator' and postulate that it should be understood to stand for a transmedial concept.

An overarching virtual communicating mind that is the perceiver of overarching communication $=$ an overarching virtual communicatee. While a perceiver of a media product (an actual communicatee) may have no knowledge of, access to, or interest in the actual communicator, an actual communicatee must be supposed to be aware of and have a certain amount of control of herself. Thus, there is no need to involve an overarching virtual communicating mind that perceives the overarching communication-an 'overarching virtual communicatee'-because the actual communicatee is out of reach. However, an overarching virtual communicatee may, just like an overarching virtual communicator, be helpful for making the virtual sphere comprehensible. In cases where the actual communicatee has a sense of not being an adequate perceiver at all, or when she 
believes that only parts of what is being communicated is graspable, it may be useful or even necessary to construe a virtual sphere including an overarching virtual communicatee. It is about construing an ideal perceiver's mind that might be able to grasp the entirety in a better way than the actual communicatee and hence achieve fuller understanding and better coherence (the concept of overarching virtual communicatee is a transmedial variation of what is known in literary theory as "implied reader" [Booth 1961]). In other words: the overarching virtual communicatee is the type of actual communicatees that is best suited for perceiving the media product. This ideal type of communicatee is something that may emerge within the virtual sphere as a result of the thought activity of the actual communicatee. Sometimes it is superfluous. As the concept of overarching virtual communicator, the concept of overarching virtual communicatee is profoundly transmedial and does not rely on the modality modes of the media products.

An overarching virtual communicating mind that is the perceiver of overarching narration = an overarching virtual narratee. The 'overarching virtual narratee' is a variation of the overarching virtual communicatee, of which nothing more must be said except that the exploration of narratees at different levels in literature was pioneered by Prince (1982: 16-26) in a way that has inspired this account.

An embedded virtual communicating mind that is the producer of embedded communication $=$ an embedded virtual communicator. It is common for communication to be about communication. When talking to each other, one may mention other people who have said things or communicated them in other ways. Still images may depict acts of communication such as speaking, writing, drawing, or gesticulating. In all of these cases, one infers that communicating minds are involved in what is being represented. When seeing a still image of a writing person, for instance, one considers that the represented person must have a mind - a virtual mind, of course - that directs the writing performed by the directly represented body. In a case like this, the virtual sphere being formed by the perception of the static, visual, and iconic media product includes an embedded virtual communicating mind that is the producer of embedded communication; or, more succinctly, an 'embedded virtual communicator'. Virtual communicators like these are embedded, not overarching, because they only constitute smaller or larger parts of the virtual sphere, in contrast to overarching virtual communicators that have bearing on the totality of the virtual sphere. Although embedded virtual communicators, like overarch- 
ing virtual communicators, emerge within the intracommunicational domains, they may more or less resemble minds in the extracommunicational domain. A virtual sphere may contain no, one, or several embedded virtual communicators.

An embedded virtual communicating mind that is the producer of embedded narration = an embedded virtual narrator. The 'embedded virtual narrator' is a special case of the embedded virtual communicator. It must be noted that literary theory in particular has come up with a multitude of terms and concepts that connect to the discussions here, although they are too media-specific to be relevant for a treatise on transmedial narration.

An embedded virtual communicating mind that is the perceiver of embedded communication = an embedded virtual communicatee. As already stated, it is common for communication to be about communication, and of course it is not only communicators, but also communicatees, that can be represented in communication. To reformulate the previous examples: When talking to each other, people may mention other people having listened to, seen, or in other ways perceived media products. Still images may depict acts of communication such as speaking, writing, drawing, or gesticulating, but also people listening to, sensing, or watching various media products, and we must then infer that these represented people have virtual minds that process the perceived sensory configurations. In alignment with embedded virtual communicators, a virtual sphere may harbor none, one, or several 'embedded virtual communicatees'.

An embedded virtual communicating mind that is the perceiver of embedded narration = an embedded virtual narratee. 'Embedded virtual narratees' are nothing more or less than specific forms of embedded virtual communicatees.

And so on; multiple layers of communication or narration embedded in embedded communication or narration. Continuing these lines of reasoning, embedded communication and narration may embed further layers of communication and narration. Communication or narration embedded in embedded communication or narration follow the same principles as communication or narration that is simply embedded in communication or narration. However, in contrast to overarching virtual communicators, communicatees, narrators, and narratees, embedded virtual communicators, communicatees, narrators, and narratees are to some extent sensitive to modality modes and therefore not fully transmedial.

Media types involving sophisticated systems of symbols, such as media including visual, auditory, or tactile verbal language, may easily represent 
infinite layers of embedded communication: 'Sarah said that she had read in a book that scientists claim that people who eat much sugar report that ...' Also, media types involving visual icons (whether fully spatiotemporal or three- or two-dimensionally spatial) have great potential for representing several layers of embedded communication. We have all seen images of people creating images of people creating images of people creating images ad infinitum. However, it is not as easy for these iconic media types to represent several layers of embedded narration if they are not temporal. Moving images may readily represent events in succession that include narrative events, such as when we see a story about someone going to the cinema, buying tickets, and then watching a movie about someone going to her desk, sharpening a pen, thinking a while, and then writing a letter about a friend who has traveled to Indonesia and fallen in love-and so forth. Still images, on the other hand, are less adequate for representing temporal interrelations being represented within other temporal interrelations, although it is certainly not impossible, especially if the perceiver's background knowledge is explored. In the case of media types that are recognized as potentially narrative only in a more elementary mannersuch as a meal where the interrelated events consist of tastes and taste combinations that are developed and contrasted - the idea of representing embedded narratives offers even more resistance due to the limited amount of complex cognitive functions connected to the gustatory sense. As a rule of thumb, I propose that embedded narration is even more media-sensitive than narration as such, and that the deeper down in embedded narrative layers one goes, the less transmedial it all becomes.

\section{FOCALIZING Minds}

For a long time, narratology has, for good reasons, scrutinized concepts such as perspective and point of view and in numerous ways related them to narration and narrators. The related concept of focalization was first investigated by Gérard Genette in written literature (1980 [1972]: 186) and was later explored by, among many others, François Jost in film (2004), Kai Mikkonen in comics (2011), and Jonathan Hensher in still images (2016). There is an extensive literature on the entangled issues of perspective, point of view, focalization, and their interrelations (for a recent overview with a transmedial perspective, see Thon 2016: 223-264).

Focalization is variously conceptualized in terms of agency or functions that somehow delimit narratives and parts of narratives: not everything is seen, heard, or conveyed in a certain narrative. The scope of narratives can 
hence be understood to be restricted by one or several focalizers. Although originating from literary theory, focalization is actually a profoundly transmedial concept that, I believe, must be tightly connected to the concept of communicating and narrating minds.

It is often noted that the term 'focalization' has certain visual connotations. It is "based on the visual metaphor of a lens through which one can take things, characters, actions in the storyworld into 'focus'. It seems that a media-sensitive narratology has to revise this concept to accommodate all the other sense perceptions, too" (Mildorf and Kinzel 2016a: 14). While it is vital to revise the concept so that it clearly covers all forms of sense perceptions, this does not necessarily include revising the term. Several new terms have actually been coined for focalization of other sense perceptions than the visual, but I think it is untenable to use different terms for each different sense being involved, just as it is untenable to use different terms for narration and narrators in different media types. Such a practice would make transmedial terminology acutely overloaded and transmedial research unnecessarily cumbersome. As the term 'focus' is far from exclusive to the visual domain-it is broadly used for denoting points of convergence, attention, or action in a wide array of sensorial and cognitive domains-I find the term 'focalization' useful for transmedial narratology. Therefore, I prefer to continue talking about focus, focalizing, and focalization in all media types instead of introducing a broad range of new media-specific terms.

However, the concept of focalization is also highly useful outside the area of narration. For that reason, I define focalization as a main feature of communication at large. All virtual spheres are demarcated in various ways. The notion of actual and virtual communicators always communicating everything they perceive and know is clearly absurd, so it must be concluded that communicators of all kinds are generally also focalizers to some extent (pace Genette and despite the broad range of knowledge of so-called omniscient narrators). In order to cover the complex field of possible restrictions of what is being communicated, it is also vital to emphasize that focalization concerns not only restrictions on the communication of all kinds of sensory perceptions but also restrictions on all kinds of knowledge, thoughts, ideas, and values. As the awareness of sensory perception and cognition takes place in minds, it is minds that have the ability to select what is to be communicated; therefore, focalization must be performed by focalizing minds.

Focalization is an essential and unavoidable aspect of communication in general. As communication on all levels is entirely dependent on minds, 
from the actual communicators and communicatees to embedded virtual communicators and communicatees, focalization is located in minds on the different levels that have been described in this chapter. The actual communicator determines - consciously or unconsciously-certain frames of what to be communicated. When construing the virtual sphere, the actual communicatee furthermore interprets the communicated in terms of virtual narrators focalizing their sense impressions and cognition in various ways.

Therefore, focalization regulates the communicated, both in whole and in detail. From the broadest perspective, the limits of a mind's perceptions and cognitions also constitute a form of focalization: one can never communicate what is outside one's scope, so the presence of a certain virtual mind may result in the communicated being focalized in a way that would not be the case if another virtual mind, harboring other perceptions and cognitions, had been present. By the same token, actual minds can, naturally, only (try to) communicate what they have perceived and what they know or believe. From a narrower perspective, focalization is rather about choosing - for practical or more calculated reasons - to delimit the scope. As communicating minds may choose to pay attention to what they know about other minds, one of many ways of focalizing is to delimit one's scope to what one assumes to be the perceptions, knowledge, and ideas of other minds. Clearly, different minds within the same virtual sphere may focalize in ways that create tensions or even conflicts-clashes that may or may not be satisfactorily resolved by an overarching virtual narrator.

Overall, I believe that a clear notion of different levels of communicating, narrating, and focalizing minds is highly useful for understanding how communication at large and narration in particular is structured. It is essential that the conceptual framework is thoroughly transmedial, while at the same time pointing to the limits of transmediality. In the following chapter, where the attention will be on represented events, it should be borne in mind that events may appear both in narratives that actual or overarching virtual narrators are responsible for, and in narratives produced by embedded virtual narrators.

\section{REFERENCES}

Alber, Jan. 2010. Hypothetical intentionalism: Cinematic narration reconsidered. In Postclassical Narratology: Approaches and Analyses, ed. Jan Alber and Monika Fludernik, 163-185. Columbus: Ohio State University Press. 
Booth, Wayne C. 1961. The Rhetoric of Fiction. Chicago: University of Chicago Press.

Diehl, Nicholas. 2009. Imagining de re and the symmetry thesis of narration. Journal of Aesthetics \& Art Criticism 67: 15-24.

Gaudreault, André. 2009 [1988]. From Plato to Lumière: Narration and Monstration in Literature and Cinema. Translated by Timothy Barnard. Toronto: University of Toronto Press.

Genette, Gérard. 1980 [1972]. Narrative Discourse: An Essay in Method. Translated by Jane E. Lewin. Ithaca, NY: Cornell University Press.

Hensher, Jonathan. 2016. Glimpsing the devil's tale? Towards a visual narratology of the fantastic in illustrated editions of Cazotte's Le Diable amoureux. Journal for Eighteenth-Century Studies 39: 663-681.

Jost, François. 2004. The look. From film to novel: An essay in comparative narratology. In A Companion to Literature and Film, ed. Robert Stam and Alessandra Raengo, trans. Robert Stam, 71-80. Malden, MA: Blackwell.

Mikkonen, Kai. 2011. Graphic narratives as a challenge to transmedial narratology: The question of focalization. Amerikastudien/American Studies 56: 637-652.

Mildorf, Jarmila, and Till Kinzel. 2016a. Audionarratology: Prolegomena to a research paradigm exploring sound and narrative. In Audionarratology: Interfaces of Sound and Narrative, ed. Jarmila Mildorf and Till Kinzel, 1-26. Berlin and Boston: de Gruyter.

Prince, Gerald. 1982. Narratology: The Form and Functioning of Narrative. Berlin: Mouton.

Thon, Jan-Noël. 2016. Transmedial Narratology and Contemporary Media Culture. Lincoln and London: University of Nebraska Press.

Open Access This chapter is licensed under the terms of the Creative Commons Attribution 4.0 International License (http://creativecommons.org/licenses/ by $/ 4.0 /)$, which permits use, sharing, adaptation, distribution and reproduction in any medium or format, as long as you give appropriate credit to the original author(s) and the source, provide a link to the Creative Commons licence and indicate if changes were made.

The images or other third party material in this chapter are included in the chapter's Creative Commons licence, unless indicated otherwise in a credit line to the material. If material is not included in the chapter's Creative Commons licence and your intended use is not permitted by statutory regulation or exceeds the permitted use, you will need to obtain permission directly from the copyright holder.

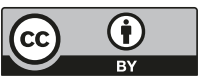

